\title{
Contribuições de Edith Penrose às Teorias do Progresso Técnico na Concorrência Oligopolista
}

\author{
Contributions of Edith Penrose to the theories of technical \\ progress within oligopolistic competition
}

TAMÁS SZMRECSÁNYI*

RESUMO: Este artigo revisa as contribuições de Edith T. Penrose (1914-1996) às teorias do progresso técnico dentro da competição oligopolística. Baseia-se principalmente no capítulo VII de sua seminal Teoria do Crescimento da Empresa, publicada pela primeira vez em 1959.

PALAVRAS-CHAVE: História do pensamento econômico; Penrose; competição oligopolista.

ABSTRACT: This paper reviews the contributions of Edith T. Penrose (1914-1996), to the theories of technical progress within oligopolistic competition. It is mainly based upon chapter VII of her seminal Theory of the Growth of the Firm, published for the first time in 1959. KEYWORDS: History of economic thought; Pensore; oligopolistic competition.

JEL Classification: B21; B31; D43.

Em várias idiomas, a palavra "economista" é usada indistintamente para designar os homens a as mulheres que trabalham neste mister. Apesar disso, a participação feminina na profissão, e mais particularmente no desenvolvimento científico da disciplina, continua sendo pequena a relativamente recente no mundo todo. Numa listagem feita por Blaug ( 1986), incluindo cerca de mil economistas, encontramos apenas os nomes de 28 mulheres. Conseqüentemente, Edith Tilton Penrose (cujo nome, estranhamente, não figura nessa listagem) pode ser considerada uma das pioneiras nesse âmbito. Mas, a sua importância provém, acima de tudo, do valor, de sua obra, de grande influência no pensamento econômico contemporâneo.

\footnotetext{
* Professor Titular do Departamento de Política Cientifica e Tecnológica do Instituto de Geociências da Universidade de Campinas: Unicamp, Campinas/SP, Brasil. E-mail: tszmrecsanyi@uol.com.br
} 


\section{VIDA E OBRA}

Nasceu em 1914 na cidade de Los Angeles, onde também obteve seu bacharelado em Economia na Universidade da Califórnia. Depois da morte de seu primeiro marido, mudou-se para Baltimore, na costa leste dos Estados Unidos, all completando seus estudos de pós-graduação (mestrado e doutorado) na Universidade Johns Hopkins, sob a orientação de Fritz Machlup. Foi também all que conheceu o seu segundo marido, o economista a professor Ernest F. Penrose (falecido em 1984), de quem foi inicialmente auxiliar e assistente, primeiro na Organização Internacional do Trabalho, em Genebra e Montreal (1939-41), e mais tarde da embaixada norte-americana em Londres (1941-46).

Ao final dos anos 40, ambos voltaram para Baltimore, a fim de retomarem suas respectivas carreiras acadêmicas na Universidade Johns Hopkins. Mas, essa tentativa acabou sendo parcialmente frustrada: por causa do macartismo, o casal foi compelido a expatriar-se ${ }^{1}$. Devido a isso, Edith Penrose veio a trabalhar sucessivamente na Australian National University, em Camberra (1955/56), na Universidade de Bagdá, no Iraque (entre 1957 e 1959), para finalmente chegar de volta a Londres em 1960. Permaneceu na capital britânica durante a maior parte das duas décadas subseqüentes, só se afastando dela para breves estágios docentes em Dar-es-Salaam, na Tanzânia (em 1971/72), e em Toronto, no Canadá (em 1977).

Nos anos iniciais desta sua segunda estada em Londres, Edith Penrose deu aulas tanto na London School of Economics como na School of Oriental and African Studies, da Universidade de Londres, até a sua nomeação de professora titular de Economia desta última, posto que manteve de 1964 a 1979. Entre 1977 a 1984, foi professora visitante do INSEAD, a famosa escola francesa de administração de empresas sediada em Fontainebleau. Lecionou também no Templeton College, da Universidade de Oxford (de 1982 e 1985), a na Bradford University (entre 1989 a 1992). Depois de ter se aposentado, veio a falecer em 1996 na sua casa de campo perto de Cambridge.

Além de numerosos artigos avulsos, publicou três importantes livros de Economia Aplicada: Economics of The International Patent System (1951), The Large International Firm in Developing Countries: the International Petroleum Industry (1968), e The Growth of Firms, Middle East and Other Essays (1971). Neles discute problemas de grande atualidade e fundamental importância como a economia das patentes, o funcionamento da indústria do petróleo, e a atuação das empresas multinacionais. A sua última obra de peso, escrita em co-autoria com o marido, versou sobre o Iraque, e foi publicada em 1978. Mas, a sua principal contribuição a nossa disciplina foi, sem dúvida, de caráter teórico, materializada no livro The Theory of the Growth of the Firm, publicada pela primeira vez em 1959, e reeditado em 1980 e 1995.

\footnotetext{
${ }^{1}$ Cf. Cairncross (1996). Sobre a biografia de Edith Penrose, veja-se também o artigo de Mabro (1996) e o sucinto verbete de Marris (1991).
} 


\section{UM LIVRO NOTÁVEL}

Trata-se de um livro de economia notável sob vários aspectos, inclusive pelo fato de não conter quaisquer tabelas, gráficos, fórmulas ou equações, a de estar escrito em boa prosa do começo ao fim - contrariamente ao que ocorre com os textos da maioria de nossos colegas de profissão. A leitura desse livro é agradável, mas também difícil, devendo ser feita com lápis ou caneta à mão, devido à riqueza e ao grau de elaboração das idéias, conceitos e propostas que o trabalho apresenta. Conceitos, idéias e propostas que são, ao mesmo tempo, originais e profundos, além de formalmente sugestivos e matematicamente esquematizáveis. Dele só irei abordar um aspecto, qual seja, o que trata da relação entre o crescimento das empresas de nosso tempo (principalmente das grandes) e o progresso técnico induzido pela pesquisa científica e tecnológica ${ }^{2}$

Sob este ponto de vista, a matriz do pensamento de Edith Penrose é nitidamente schumpeteriana - como ela mesma faz, aliás, questão de reconhecer repetidas vezes no seu livro ${ }^{3}$. Mas, essa relação acaba assumindo um significado especifico no contexto de sua própria teoria - uma teoria baseada em idéias simples, relativamente pouco numerosas, mas dotadas de grande força e consistência lógica, passíveis de serem testadas empiricamente.

O objeto de estudo de Penrose é a empresa industrial moderna no sistema capitalista dos últimos cem anos. Empresa que é tomada por ela em termos históricos concretos, como organização humana detentora de um conjunto de recursos que lhe é especifico. Trata-se de algo muito distante da abstração formalmente postulada pela "teoria da firma" dos economistas neoclássicos.

A empresa, para Penrose, constitui uma entidade integrada por pessoas e recursos, capaz de sobreviver a seus fundadores, de crescer e desenvolver-se através do tempo, e — o que parece ainda mais importante — apta a planejar não apenas as suas atividades correntes, mas também o seu futuro. Uma das preocupações centrais da autora é caracterizar teoricamente a natureza institucional das empresas e os mecanismos do crescimento delas ao longo do tempo.

Essa capacidade de crescer não tem limites a médio e a longo prazos, inexistindo para Penrose a noção de um tamanho ótimo, ou mais lucrativo por definição. As grandes empresas, segundo ela, não apenas tendem a ser freqüentemente muito bem sucedidas em seus intentos neste sentido, como têm se revelado perfeitamente capazes de crescer e expandir-se indefinidamente ${ }^{4}$. Trata-se de algo que pode ser

\footnotetext{
2 Trata-se de um aspecto pouco estudado da sua obra, quer pela própria autora (no seu prefácio à terceira edição do livro), quer pela maioria de seus comentaristas. Nas análises feitas por estes últimos, só encontrei algumas referencias esparsas num artigo de Moss (1984), pp. 62-65, a noutro de Christensen (1994), pp. 1718 e 1724.

${ }^{3}$ Veja-se, por exemplo, Penrose (1980), pp. 106 e 113-4.

${ }^{4}$ Idem, p. 32.
} 
empiricamente constatado pelas idades mais do que centenárias de muitas das grandes empresas multinacionais de nosso tempo.

É apenas a curto prazo que essa capacidade de crescer parece longe de estar assegurada incondicionalmente, dependendo a cada momento da capacidade gerencial dos administradores da empresa em questão, das suas condições de mercado, bem como dos riscos e da incerteza que cercam todas e quaisquer atividades econômicas, ou seja, dependendo tanto de fatores internos como das condições externas à mesma.

A principal diferença que existe entre esses dois horizontes cronológicos reside no aumento de experiências e de conhecimentos através do tempo, fazendo surgir, de um lado, novas oportunidades inexistentes e independentes do meio, e do outro, conferindo um alto grau de autonomia e de especificidade à trajetória de cada empresa. As referidas experiências e conhecimento vão surgindo e se desenvolvendo de duas maneiras: através do aprendizado formal de noções objetivas a transmissíveis - que correspondem ao chamado "estado das artes"; e através da vivência pessoal e subjetiva dos integrantes de qualquer empresa. Tanto esta como aquelas vão se acumulando em termos da quantidade de noções adquiridas, e da capacidade de vir a utilizá-las produtivamente ${ }^{5}$.

É a inter-relação do aumento desses conhecimentos internalizados com as mudanças nas condições externas à empresa que faz surgir as oportunidades para o seu crescimento através do tempo, Contrariamente à maioria dos demais economistas, Edith Penrose dá menos importância às condições externas — ou seja, ao mercado - do que aos fatores internos do crescimento das empresas. Fatores esses que, segundo ela, vão se traduzindo e integrando numa busca permanente do pleno uso produtivo de todos os recursos humanos e materiais disponíveis dentro de cada empresa.

Tais recursos, além de serem quantitativa e qualitativamente mutáveis através do tempo, possuem um valor econômico fundamentalmente determinado pelos serviços que são capazes de proporcionar. Os serviços obteníveis de cada recurso vinculam-se diretamente à acumulação de experiências e conhecimentos, que mencionamos há pouco. A acumulação desses recursos pode ser, e tem sido na prática, induzida e/ou acelerada por meio da pesquisa científica e tecnológica.

\section{O PAPEL DA PESQUISA}

O desenvolvimento desta, particularmente (mas não apenas) nos EUA, tem muito a ver com a expansão e com a diversificação de atividades, de produtos e de processos produtivos das grandes empresas industriais do nosso tempo ${ }^{6}$. É na análise dessas transformações, efetuada principalmente no capitulo VII de seu livro,

\footnotetext{
${ }^{5}$ Idem, pp. 52-3.

${ }^{6}$ Idem, pp. 76-7.
} 
que podemos encontrar algumas das mais importantes contribuições teóricas da Autora. Por meio delas, demonstra como e por que as empresas mais eficientes (geralmente de grande porte) tendem a ser não apenas altamente diversificadas, como extensamente integradas ${ }^{7}$.

Um dos meios para tanto tem sido a implantação, expansão e multiplicação dos laboratórios de pesquisas industriais dessas empresas, sediadas nos EUA e em outros países capitalistas avançados. Desses laboratórios é que tem surgido a maior parte das inovações tecnológicas de nossa época, inerentes ao desenvolvimento das sociedades urbanas e industriais em que vivemos, além de garantidoras da manutenção quer da criatividade, quer da capacidade de crescimento, tanto das próprias empresas como do sistema econômico que elas integram.

Entre as características essenciais da diversificação de atividades, produtos e processos das empresas deve ser destacada a forma especializada pela qual ela se desenvolve. Essa especialização, que também se aplica ao crescimento por via da aquisição de outras empresas, constitui uma decorrência do aprofundamento tecnológico proporcionado pela pesquisa industrial. É ela que impede que a diversificação de produtos, processos e atividades da empresa resulte num abandono abrupto das suas atividades, processos e produtos de origem - ou do que Edith Penrose define como "bases produtivas" ou "áreas de especialização" da empresa.

Trata-se de bases e áreas essencialmente tecnológicas, cuja manutenção e consolidação através do tempo são tidas de fundamental importância para a preservação e/ou melhoria da posição competitiva das empresas ${ }^{8}$. No contexto oligopolista de nosso tempo, a competitividade das empresas nos mercados em que atuam vincula-se em última instância à capacidade tecnológica que elas demonstram possuir. E essa capacidade tecnológica é adquirida por elas ao longo do tempo, em boa parte através dos seus investimentos em pesquisa ${ }^{10}$.

Nas economias capitalistas mais avançadas, esses investimentos já se tornaram corriqueiros, sendo realizados na maioria das vezes dentro das próprias empresas, nos seus respectivos laboratórios de pesquisa ${ }^{11}$. Isto se deu primeiro e principalmente nos EUA (e também na Alemanha), onde tais laboratórios têm participado ativamente do processo schumpeteriano de "destruição criadora" - quer gerando inovações tecnológicas de todo tipo, quer procurando (e ás vezes conseguindo) antecipar-se às inovações das empresas concorrentes ${ }^{12}$.

\footnotetext{
${ }^{7}$ Ao final desse capitulo fundamental, o mais longo de todo o livro, Penrose descreve os processos históricos de expansão e diversificação de duas grandes empresas norte-americanas: a General Motors e a General Mills. Op. cit., pp. 120-6.

${ }^{8}$ Idem, pp. $109-10,115$ e 118.

9 "O processo schumpeteriano de destruição criadora não destruiu a grande empresa; antes pelo contrário, obrigou-a a tornar-se cada vez mais criativa." Op. cit., p. 106, grifos da autora.

${ }^{10}$ Idem, p. 112. Veja-se também a respeito o trabalho de Solo (1951), citado por Edith Penrose.

${ }^{11}$ Op. cit., p. 106

12 Idem, pp. 113-5.
} 
Os estímulos às inovações podem vir tanto de restrições encontradas no processo produtivo (em termos de custos, qualidade ou produtividade), como de oportunidades surgidas nos mercados. Além disso, como realça Edith Penrose, qualquer laboratório de pesquisa industrial em pleno funcionamento torna-se capaz de gerar os seus próprios projetos de investigação ${ }^{13}$. A pesquisa, como ela mesma diz, é, acima de tudo, uma atividade especulativa ${ }^{14}$. Porisso, nada garante que os novos conhecimentos e os novos serviços produtivos gerados por ela se refiram apenas à produção corrente da empresa. Antes pelo contrário, eles poderão até ser inúteis para ela a curto prazo, e, mesmo assim, virem a proporcionar-lhe mais adiante os fundamentos necessários para a aquisição de capacidade competitiva numa área inteiramente nova ${ }^{15}$.

As atividades de pesquisa industrial, devido a seus altos custos e à lenta maturação de seus resultados, constituem via de regra um privilégio das empresas de grande porte ${ }^{16}$. Por isso, a superioridade destas, em relação às pequenas e médias empresas, não é apenas econômica e financeira, mas também — e talvez principalmente - tecnológica. É esta superioridade que lhes confere uma maior flexibilidade nos processos de diversificação, de expansão, e de integração vertical ${ }^{17}$.

Nunca é demais assinalar que a manutenção dessas vantagens através do tempo requer contínuos, cumulativos, e às vezes crescentes investimentos em pesquisa ${ }^{18}$. Trata-se de um requisito cuja satisfação envolve não apenas as necessárias disponibilidades de capital para tanto, mas também a existência de uma percepção consistente das vantagens obteníveis através do progresso técnico. As oportunidades para a ocorrência deste não são espontâneas e aleatórias, mas precisam ser constantemente criadas e construídas.

\section{REFERÊNCIAS BIBLIOGRÁFICAS}

BLAUG, Mark, ed. (1986) Who's Whoin Economics: A Biographical Dictionary of Maior Economists, 1700-1986, $2^{a}$ edição (Cambridge, MA, 1986, MIT Press).

CAIRNCROSS, Alec (1996), "Professor Edith Penrose", The Jndependent, 19 outubro 1996, p. 20. CHRISTENSEN,J.F.(1994)"Analyzing the Technology Base of the Firm: a Multi-Dimensional Resource and Capability Perspective", paper para a EUNETIC Conference on Evolutionary Economics of Technological Change, University Louis Pasteur Strasbourg, outubro de 1994, vol. 3 , pp. $1.717-40$.

\footnotetext{
13 Idem, p. 114, nota 3.

14 Idem, p. 116.

15 Idem, pp. 114-5.

16 Idem, pp. 115-6.

${ }^{17}$ Idem, pp. 118-9.

18 Idem, pp. 132-3.
} 
MABRO, Robert (1996), “Edith Penrose: a Tribute” ,journal of Energy Literature, 11.2, 1996, pp. 56-61.

MAR RIS (1991 ), “Penrose, Edith Tilton”. New Palgrave, vol. III (London, 1991, Macmillan), p. 831.

MOSS, S. J. (1984) "Imbalance Theory and the Analysis of Investment and Technical Change by Firms", Journal of Economic Studies, 11(2), 1984, pp. 61-74.

PENROSE, E. T. (1980) The Theory of the Growth of the Firm, 2a edição (Oxford, 1980, Basil Blackwell).

SOLO, C. S. (1951) "Innovation in the Capitalist Process: a Critique of the Schumpeterian Theory", Quarterly Journal of Economics, LXV (3), agosto de 1951, pp. 417-28. 